\title{
COMPUTATIONAL PREDICTION OF WATER-FLOW CHARACTERISTICS IN SPIRAL SEPARATORS: PART I, FLOW DEPTH AND TURBULENCE INTENSITY
}

\author{
Doheim, M. A*., Abdel Gawad , A. F. **, Mahran, G. M. A. ${ }^{* * *}$ \\ Abu-Ali, M. H.*, and Rizk, A. M.*
}

* Mining and Metallurgical Eng. Dept., Faculty of Engineering, Assiut Univ. ** Mechanical Power Eng. Dept., Faculty of Engineering, Zagazig University. *** Mining and Petroleum Eng. Dept. Faculty of Engineering, Al-Azhar Univ.

(Received April 17, 2008 Accepted May 13, 2008)

A spiral separator is one of the commonly-used gravity-concentration devices. It has been widely used in the mineral processing of coal. Also, it is used for the inexpensive pre-concentration of low grade ores. Spiral separator consists of an open trough that twists downward in helical configuration about a central axis. The aim of the present study is the simulation of the flow of water in spiral separators. The study is based on volume of Fluid (VOF) approach and turbulence modeling. The results focus on water-flow characteristics such as the depth of water as well as the turbulence intensity. The results demonstrated that the water depth and turbulence intensity on spiral trough increase smoothly outward. Predicted results are compared with the experimental findings from LD9 coal spiral. Comparison between the predicted and the measured values show good agreement and the most accurate turbulence model is RSM.

KEYWORDS: Spiral separator, Free-surface flow, Computational simulation, Turbulence modeling, Flow depth.

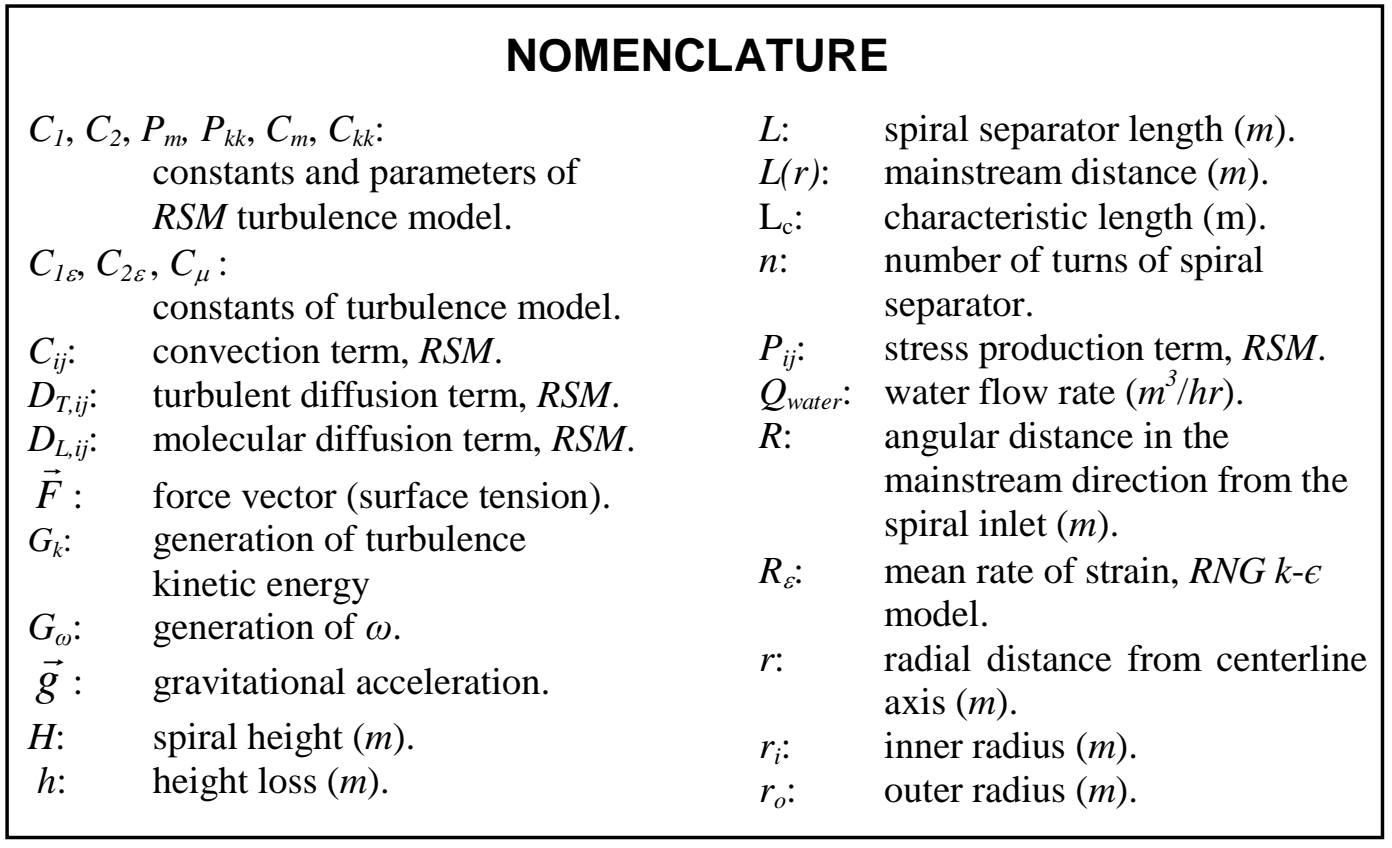




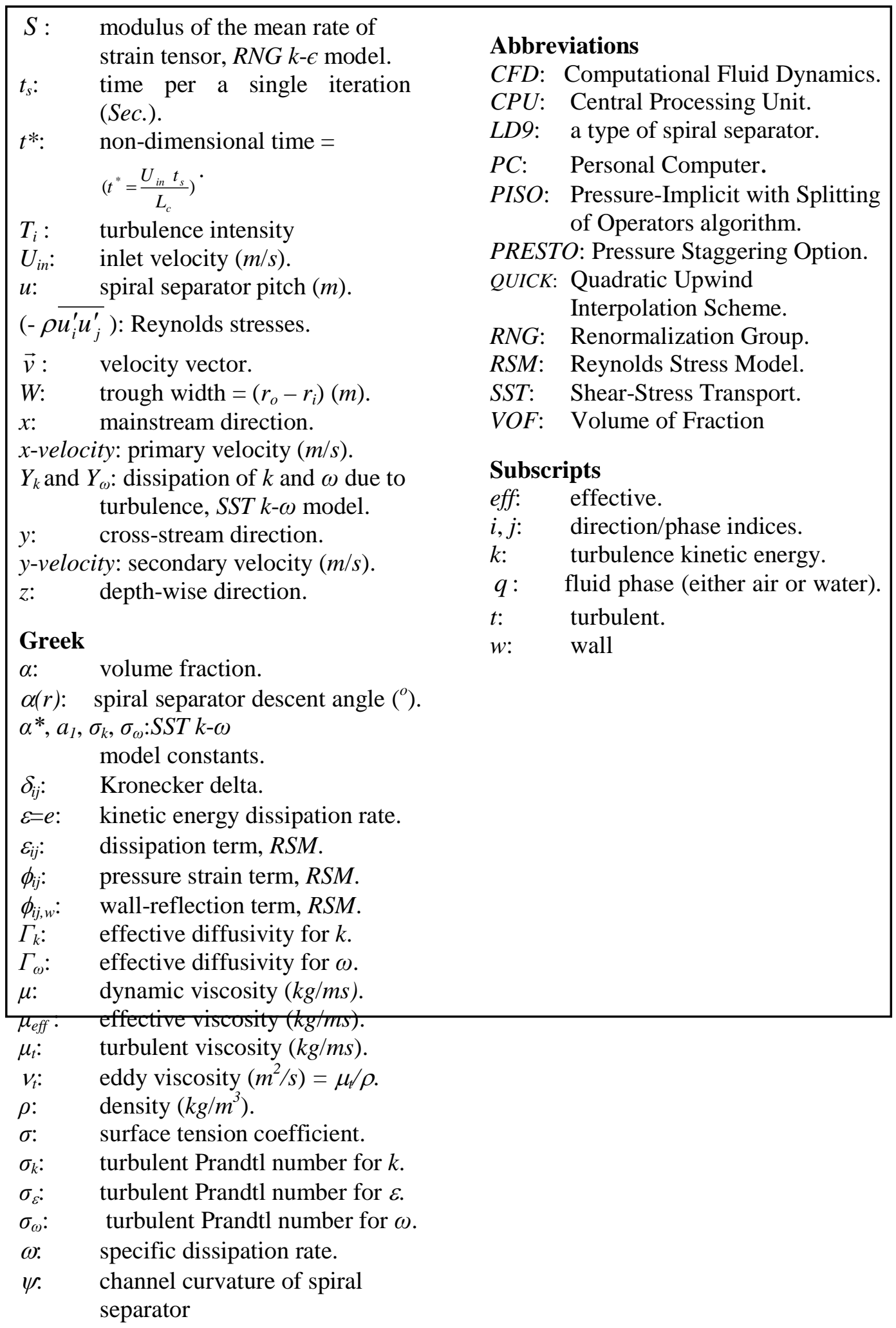




\section{INTRODUCTION}

A spiral separator is a gravity-concentration device. Because of the simplicity of their operation and low cost, spirals have widely been used in the mineral industry to separate high-density particles from low-density particles. The majority of publications concerning spirals have focused on their design and operation. Burt [1] and Wills [2] have presented a comprehensive review of such papers within the period from 1940's until the mid 1980's. It is clear that most spiral designs have evolved through empirical analysis. Many empirical models, which are based on experimental data, were reported by Tuker et al. [3], Tuker[4], Kelly et al. [5], Holland-Batt [6], Holland-Batt and Holtham [7], Holland-Batt [8], Subasinghe and Kelly [9], King et al. [10], Loveday and Cilliers [11], Atasoy and Spottiswood [12], Kapur and Meloy [13,14], and Glass et al. [15]. The drawback of these empirical models is that if the type of spiral or the minerals or the particle size range are changed, new experimental data must be collected to modify the coefficients or even to change the mathematical model itself.

A fluid flow mechanistic model or CFD is based on fluid mechanics. A mechanistic model incorporates the geometry of the device in the model. These models started by Burch [16] when he assumed the pulp to be a liquid of uniform viscosity. He also assumed that the secondary flow would not affect the primary flow. Wang and Andrews [17] introduced a first step in the development of a mechanistic model of the spiral operation. The model determines the flow fields for simplified rectangular spiral sections. Jancar et al. [18,19] investigated the fluid flow on LD9 spiral using their developed code. All these models were developed with time to be more reliable. Mathews et al. [20,21] presented CFD modeling of the fluid flow on spiral trough.

The present study introduces a two phase (water and air) computational model based on VOF method. The effect of surface tension force between water and air is taken into account. Since, the flow is turbulent in the spiral trough, four turbulence models, namely: $k-\varepsilon$, $R N G k-\varepsilon$, SST $k-\omega$, and $R S M$ models are employed. One of the objectives is to obtain the most appropriate turbulence model for the present problem. The present model is validated using the experimental data of Holtham et al. [7,22,23].

\section{SPIRAL SEPARATOR DESCRIPTION}

\subsection{Geometry of Spiral Separator}

A spiral separator consists of an open channel that wraps around the central supporting column. The number of turns ( $n$ ) varies from 3 to 10. Most modern designs [24] have 5 to 7 . The trough width usually ranges from 0.25 to $0.35 \mathrm{~m}$. The design parameters of the spiral separator can be listed as: spiral pitch $(u)$, profile shape, length $(L)$, and inner and outer trough radii (ri , ro)) that govern the curvature $(\psi)$ of the channel. The parameters are shown in Fig. 1 and defined as follows [14,15,25,26]: 
Pitch: $u=2 \pi r \tan \alpha$

(m) Curvature: $\psi=\left(r_{i}+r_{o}\right) / 2 W$ (dimensionless)

Descent angle: $\alpha(r)=\tan ^{-1}(u / 2 \pi r) \quad\left({ }^{\circ}\right) \quad$ Trough width: $W=r_{0}-r_{i}$

Height loss: $h=R r \tan (\alpha) \quad(m) \quad$ Spiral height: $H=n * u$

Mainstream distance $: L(r)=R r / \cos (\alpha)(m)$

Where, $R$ is the angular distance in the mainstream direction from the spiral inlet ( $=2 \pi$ $\alpha$, on full turn), $r$ is the radial distance from the centerline axis, $H$ is the spiral height, and $\mathrm{W}$ is the trough width. The geometrical parameters for LD9 spiral [7, 22, 26] are stated in Table 1.

\subsection{Flow Behaviour}

The fluid flow on LD9 spiral is characterized by shallow depths of 1-20 $\mathrm{mm}$ and main stream velocities of $0.3-3 \mathrm{~m} / \mathrm{s}$. The mainstream velocities increase radially outward. The secondary current, normal to the main flow direction, travels outward near the free-surface and inward near the trough base. Secondary flow is approximately an order of magnitude smaller than the mainstream component $[7,22,23]$.
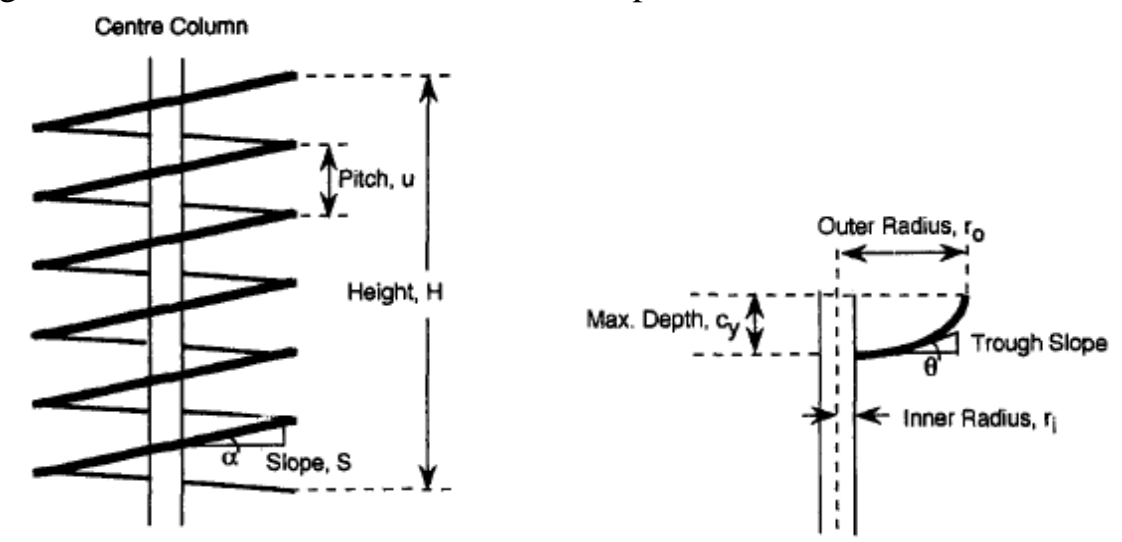

Fig. 1 Schematic drawing of a spiral separator [13].

Table (1) The geometrical parameters of LD9 spiral separator [7, 22, 26].

\begin{tabular}{|c|c|c|c|c|c|c|}
\hline $\begin{array}{c}\text { Inner } \\
\text { Radius } \\
\boldsymbol{r}_{\boldsymbol{i}}(\mathbf{m m})\end{array}$ & $\begin{array}{c}\text { Outer } \\
\text { Radius } \\
\boldsymbol{r}_{\boldsymbol{o}}(\mathrm{mm})\end{array}$ & $\begin{array}{c}\text { Trough } \\
\text { Width } W \\
(\mathbf{m m})\end{array}$ & $\begin{array}{c}\text { Pitch } \\
\mathbf{u} \\
(\mathbf{m m})\end{array}$ & $\begin{array}{c}\text { Curvature } \\
\psi\end{array}$ & $\begin{array}{c}\text { Descent } \\
\text { angle } \\
\alpha\left(^{\boldsymbol{o}}\right)\end{array}$ & $\begin{array}{c}\text { Number } \\
\text { of Turns } \\
\boldsymbol{n}\end{array}$ \\
\hline 70 & 350 & 280 & 273 & 0.75 & $7-32$ & 6 \\
\hline
\end{tabular}

\section{GOVERNING EQUATIONS AND COMPUTATIONAL ASPECTS}

\subsection{Governing Equations}

For modeling the free-surface flow on spiral separator, two-phase flow (air and water) is considered. The Volume of Fluid (VOF) model $[27,28]$ can model two or more immiscible fluids. A single set of momentum and continuity equations is used for the volume fraction of each of the fluids throughout the domain. The flow on a spiral 
separator is considered Newtonian and turbulent. Continuity and Navier-Stokes equations supplemented by a suitable turbulence model are appropriate for modeling the spiral separator flow. The following transient equations describe the conservation of mass and momentum equations.

\subsubsection{Continuity Equation}

Continuity equation for the volume fraction of one (or more) of the phases takes the following form,

$$
\frac{\partial}{\partial t}\left(\alpha_{q} \rho_{q}\right)+\nabla \cdot\left(\alpha_{q} \rho_{q} \vec{v}_{q}\right)=0
$$

where, $\rho$ is the fluid density, $\alpha$ is the volume fraction, $\vec{v}$ is the velocity vector, $q$ is the fluid phase (either air or water). The volume fractions of all phases sum to unity.

$$
\sum_{q=1}^{n} \alpha_{q}=1
$$

The $q^{\text {th }}$ fluid's volume fraction in the cell is denoted as $\alpha_{q}$. Then, the following three conditions are possible: $\alpha_{q}=0$ : the cell is empty (of the $q^{\text {th }}$ fluid). $\alpha_{q}=1$ : the cell is full (of the $q^{\text {th }}$ fluid). $0<\alpha_{q}<1$ : the cell contains the interface between the $q^{\text {th }}$ fluid and one or more other fluids. In general, for an $\mathrm{n}$ phase system, the volume-fractionaveraged density takes the following form:

$$
\rho=\sum_{q=1}^{n} \alpha_{q} \rho_{q}
$$

All other properties (e.g., viscosity, surface tension) are computed as stated.

\subsubsection{Momentum Equation}

The momentum equation (4) is dependent on the volume fractions through the properties $\rho$ and $\mu$.

$\frac{\partial}{\partial t}(\rho \vec{v})+\nabla \cdot(\rho \vec{v} \vec{v})=-\nabla p+\nabla \cdot\left[\mu_{t}\left(\nabla \vec{v}+\nabla \vec{v}^{T}\right)\right]+\rho \vec{g}+\vec{F}$

Where, $\vec{F}$ is the force vector (surface tension). $\mu_{t}$ is the turbulent viscosity that is given by Eq. 9. The surface tension can be expressed as a volume force. The volume force is the source term, which is added to the momentum equation. It has the following simplified form [29],

$\vec{F}=\sigma_{i j} \frac{\rho \psi_{i} \nabla \alpha_{i}}{\frac{1}{2}\left(\rho_{i}+\rho_{j}\right)}$

Where, $\sigma$ is the surface tension coefficient.

\subsection{Turbulence Models}

The turbulence models considered in this study are the standard $k-\epsilon$ model, the $R N G$ $k-\epsilon$ model, the SST $k$ - $\omega$ model, and the Reynolds-stress model (RSM).

\subsubsection{The Standard $k-\epsilon$ Model}

The turbulence kinetic energy, $k$, and its rate of dissipation, $\epsilon$, are obtained from the following transport equations [30,31], 


$$
\begin{aligned}
& \frac{\partial}{\partial t}(\rho k)+\frac{\partial}{\partial x_{i}}\left(\rho k u_{i}\right)=\frac{\partial}{\partial x_{j}}\left[\left(\mu+\frac{\mu_{t}}{\sigma_{k}}\right) \frac{\partial k}{\partial x_{j}}\right]+G_{k}-\rho \varepsilon \\
& \frac{\partial}{\partial t}(\rho \varepsilon)+\frac{\partial}{\partial x_{i}}\left(\rho \varepsilon u_{i}\right)=\frac{\partial}{\partial x_{j}}\left[\left(\mu+\frac{\mu_{t}}{\sigma_{\varepsilon}}\right) \frac{\partial \varepsilon}{\partial x_{j}}\right]+C_{1 \varepsilon} \frac{\varepsilon}{k}\left(G_{k}\right)-C_{2 \varepsilon} \rho \frac{\varepsilon^{2}}{k}
\end{aligned}
$$

Where, $G_{k}$ is the generation of turbulence kinetic energy due to the mean velocity gradient. $G_{k}$ my be defined as

$$
G_{k}=-\rho \overline{u_{i}^{\prime} u_{j}^{\prime}} \frac{\partial u_{j}}{\partial x_{i}}
$$

$\mu_{t}$ is the turbulent viscosity, and is computed by

$$
\begin{aligned}
& \mu_{t}=\rho C_{\mu} \frac{k^{2}}{\varepsilon} \\
& C_{l e} \text { (= 1.44), } C_{2 \epsilon}(=1.92), C_{\mu}(=0.09), \sigma_{k}(=1.0) \text { and } \sigma_{\epsilon}(=1.3) \text { are model constants. }
\end{aligned}
$$

\subsubsection{The RNG k- $\epsilon$ Model}

The $R N G$-based $K-\epsilon$ turbulence model is derived from the instantaneous Navier-Stokes equations. The derivation is based on a mathematical technique called "renormalization group" ( $R N G$ ) method [32]. Transport equations for the $R N G K-\epsilon$ model have a similar form to the standard $k-\epsilon$ model.

$$
\begin{aligned}
& \frac{\partial}{\partial t}(\rho k)+\frac{\partial}{\partial x_{i}}\left(\rho k u_{i}\right)=\frac{\partial}{\partial x_{j}}\left(\alpha_{k} \mu_{\text {eff }} \frac{\partial k}{\partial x_{j}}\right)+G_{k}-\rho \varepsilon \\
& \frac{\partial}{\partial t}(\rho \varepsilon)+\frac{\partial}{\partial x_{i}}\left(\begin{array}{ll}
\rho \varepsilon & { }_{i}
\end{array}\right)=\frac{\partial}{\partial x_{j}}\left(\boldsymbol{\alpha}_{\varepsilon} \mu_{\text {eff }} \frac{\partial \varepsilon}{\partial x_{j}}\right)+C_{1 \varepsilon} \frac{\varepsilon}{k}\left(G_{k}\right)-C_{2 \varepsilon} \rho \frac{\varepsilon^{2}}{k}-R_{\varepsilon}
\end{aligned}
$$

The $R N G$ turbulence model is more sensitive to the mean rate of strain because of $R_{\varepsilon}$ in Eq. 11 . Where, $G_{k}$ is calculated from Eq. 8 . The effective viscosity, $\mu_{\text {eff }}$ is given by $\mu_{\text {eff }}=\mu\left(1+\sqrt{\frac{C_{\mu} \rho k}{\mu \sqrt{\varepsilon}}}\right)^{2}$

The main difference between the RNG and standard $k-\epsilon$ models lies in the additional term in the $\epsilon$ equation and is given by

$R_{\varepsilon}=\left\{\frac{C_{\mu} \rho \eta^{3}\left(1-\frac{\eta}{\eta_{0}}\right) \varepsilon^{2}}{1+\beta \eta^{3}}\right\} \frac{\varepsilon^{2}}{k}$

Where, $\eta=S * k / \varepsilon$, and $S$ is the modulus of the mean rate of strain tensor. The model constants are set as $C_{l e}=1.42, C_{2 \epsilon}=1.68, C_{\mu}=0.0845, \sigma_{k}=1.0$, and $\sigma_{\epsilon}=1.3$.

\subsubsection{The Shear-Stress Transport (SST) $k$ - $\omega$ Model}

The shear-stress transport (SST) $k$ - $\omega$ model blends the $k$ - $\epsilon$ and $k$ - $\omega$ models to get more accurate predictions in complex flows [33]. The shear-stress transport (SST) $k-\omega$ model takes its name because the definition of the turbulent viscosity is modified to account for the transport of the principal turbulent shear stress. This feature gives the SST $k-\omega$ model an advantage in terms of performance over both the standard $k-\omega$ model and the 
standard $k-\epsilon$ model. The turbulence kinetic energy, $k$, and the specific dissipation rate, $\omega$, are obtained from the following transport equations,

$$
\begin{aligned}
& \frac{\partial}{\partial t}(\rho k)+\frac{\partial}{\partial x_{i}}\left(\rho k u_{i}\right)=\frac{\partial}{\partial x_{i}}\left(\Gamma_{k} \frac{\partial k}{\partial x_{j}}\right)+G_{k}-Y_{k} \\
& \frac{\partial}{\partial t}(\rho \omega)+\frac{\partial}{\partial x_{i}}\left(\rho \omega u_{i}\right)=\frac{\partial}{\partial x_{j}}\left(\Gamma_{\omega} \frac{\partial \omega}{\partial x_{j}}\right)+G_{\omega}-Y_{\omega}
\end{aligned}
$$

Where, $G_{k}$ is given by Eq. $8 . G_{\omega}$ is the generation of $\omega$ and is given by

$G_{\omega}=\alpha \frac{\omega}{v_{t}} G_{k}$

$\Gamma_{k}$ and $\Gamma_{\omega}$ are the effective diffusivities for $k$ and $\omega$, respectively, and are given by

$\Gamma_{k}=\mu+\frac{\mu_{t}}{\sigma_{k}}$

$\Gamma_{\omega}=\mu+\frac{\mu_{t}}{\sigma_{\omega}}$

$\sigma_{k}$ and $\sigma_{\omega}$ are the turbulent Prandtl numbers for $k$ and $\omega$, respectively. $\mu_{t}$ is computed as follows,

$$
\mu_{t}=\frac{\rho k}{\omega} \frac{1}{\max \left[\frac{1}{\alpha^{*}}, \frac{S F_{2}}{a_{1} \omega}\right]}
$$

$Y_{k}$ and $Y_{\omega}$ are the dissipation of $k$ and $\omega$ due to turbulence. The model constants are set as $\alpha^{*}=1, a_{1}=0.31, \sigma_{k}=1.176$, and $\sigma_{\omega}=2$. For more details about SST $k$ - $\omega$ model, refer to Ref. (33).

\subsubsection{The Reynolds-Stress Model (RSM)}

The Reynolds stress model (RSM) [34] is the most accurate turbulence model. The exact transport equations for the transport of the Reynolds stresses $\left(\overline{u_{i} u_{j}}\right)$ may be written as follows:

$\frac{\partial}{\partial t}\left(\overline{u_{i} u_{j}}\right)+\frac{\partial}{\partial x_{k}}\left(U_{k} \overline{u_{i} u_{j}}\right)$ \{Convection $($ Cij $\left.)\right\}=$

Turbulent Diffusion $\left(D_{T, i j}\right)+$ Molecular Diffusion $\left(D_{L, i j}\right)$

+ Stress Production $\left(P_{i j}\right)+$ Pressure Strain $\left(\phi_{i j}\right)+$ Dissipation $\left(\varepsilon_{i j}\right)$

Of the various terms in these exact equations, $D_{L, i j}$ and $P_{i j}$ do not require any modeling. However, $D_{T, i j}$, $\phi_{i j}$, and $\varepsilon_{i j}$ need to be modeled to close the equations as follows:

$$
\begin{aligned}
& D_{L, i j}=\frac{\partial}{\partial x_{k}}\left[v \frac{\partial}{\partial x_{k}}\left(\overline{u_{i} u_{j}}\right)\right] \quad i, j, k=1,2 \& 3 \\
& P_{i j}=-\left(\overline{u_{i} u_{k}} \frac{\partial U_{j}}{\partial x_{k}}+\overline{u_{j} u_{k}} \frac{\partial U_{i}}{\partial x_{k}}\right)
\end{aligned}
$$




$$
\begin{aligned}
& D_{T, i j}=\frac{\partial}{\partial x_{k}}\left[\overline{u_{i} u_{j} u_{k}}+\frac{1}{\rho} \overline{P\left(\delta_{k j} u_{i}+\delta_{i k} u_{j}\right)}\right] \\
& =\frac{\partial}{\partial x_{k}}\left(\frac{v_{t}}{\sigma_{k}} \frac{\partial \overline{u_{i} u_{j}}}{\partial x_{k}}\right), \quad \sigma_{k}=0.82 \\
& \phi_{i j}=\frac{1}{\rho} \overline{P\left(\frac{\partial u_{i}}{\partial x_{j}}+\frac{\partial u_{j}}{\partial x_{i}}\right)} \\
& =-C_{1} \rho \frac{\varepsilon}{k}\left[\overline{u_{i} u_{j}}-\frac{2}{3} \delta_{i j} k\right]-C_{2}\left[\left(P_{i j}-C_{i j}\right)-\frac{2}{3} \delta_{i j}\left(P_{m}-C_{m}\right)\right]+\phi_{i j, w} \\
& C_{1}=1.8, C_{2}=0.60, P_{m}=0.5 P_{i j}, C_{m}=0.5 C_{i j} \text {, } \phi_{i j, w} \text { is the wall-reflection term that is }
\end{aligned}
$$

\subsection{Computational Domain}

The depth of the LD9 spiral separator is shallow $(0.001-0.015 \mathrm{~m})$ relative to its mainstream length $(2.7-15.6 \mathrm{~m})$. Thus, it is not feasible to model the complete spiral at once. Otherwise, approximately eight million cells are required. This number of cells could not be accommodated using the available personal computers (PCs). Therefore, we suggested a computational domain (Fig. 2) that consists of one complete turn of the spiral. Periodic boundary condition was applied by progressively feeding the results from the outlet cells back to the inlet. This procedure continues until fully developed conditions are reached or the computations cover the total number of $L D 9$ spiral turns. A single turn of the LD9 spiral was constructed to be the three-dimensional computational domain. The grid consists of $150 \times 200 \times 40$ cells in the mainstream $(x)$, cross-stream $(y)$ and depth-wise $(z)$ directions, respectively. This gives a total number of cells of $1,200,000$. The computational grid is a structured mesh consisting of hexahedral control volumes.

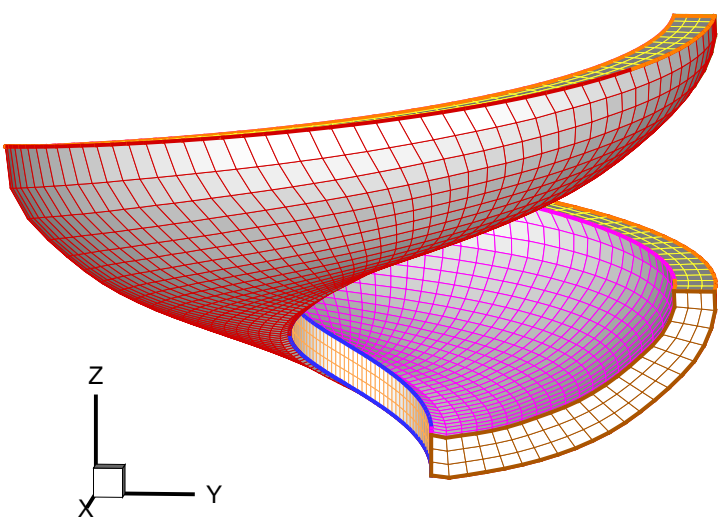

Fig. 2 Computational domain with reduced cells for clarity.

\subsection{Boundary Conditions}


The domain is surrounded by four boundaries, namely: inlet plane, outlet plane, solid wall, and free-surface of the water flow. At the inlet of the spiral, velocity components and volume fractions of water are specified to give the desired flow rates. At exit of the domain (outlet plane), velocity gradients are set to zero. At the trough wall, no-slip and no-penetration conditions are imposed. At free-surface, the volume of fluid (VOF) formulation $[27,28,35,36]$ is used. In the VOF method, the interface between two phases (water and air) is tracked on a grid that remains fixed so that the interface does not usually coincide with a grid line. The water and air phases on spiral separators are assumed to have constant physical properties. Thus, the assumed properties are $\rho_{\text {water }}=1000 \mathrm{~kg} / \mathrm{m}^{3}, \mu_{\text {water }}=0.0009 \mathrm{~kg} / \mathrm{ms}, \rho_{\text {air }}=1.225 \mathrm{~kg} / \mathrm{m}^{3}$, and $\mu_{\text {air }}=1.7894 \times 10^{-5} \mathrm{~kg} / \mathrm{ms}$. The trough wall-roughness constant was set to 0.5 .

\subsection{Numerical Treatment}

Numerical solution of the above mathematical model is based on finite volume method. The VOF distributions were solved implicitly. The equations were discretized using the Quadratic Upwind Interpolation (QUICK) scheme, The Pressure-Implicit with Splitting of Operators (PISO) algorithm was used for pressure velocity coupling. Pressure Staggering Option (PRESTO) was used for pressure interpolation scheme. The equations were solved with the unsteady solver with a time step of 0.001 Sec. Residuals of all variables were restricted to $1 \times 10^{-3}$. The geometric reconstruction was used for VOF scheme. The computations were carried out using a validated commercial code [37].

\section{RESULTS AND DISCUSSIONS}

In the present work, the numerical results are compared with the experimental studies of others $[7,22,23]$. The study focuses on the water depth on the spiral trough and the turbulence intensity of water flow.

\subsection{Water Depth}

The water accumulates toward the outer part of the spiral trough due to the forces acting on water. The water depth increases smoothly outward. Figure 3 shows comparisons between the numerical simulations and the experimental measurements $[22,23]$ of water depth for flow rates of 4, 6 and $8 \mathrm{~m} 3 / \mathrm{hr}$, respectively. It is noticed that the water depth increases with the flow rate in the outer region of the trough. Whereas, the flow rate has a minor effect on the water depth in the inner region. There is a noticeable agreement between the experimental results and the present predictions (especially, predictions of RSM). Figure 4 shows the present prediction for water depth profiles using the four turbulence models at the flow rate $4 \mathrm{~m}^{3} / \mathrm{hr}$. The predictions of the RNG $k-\varepsilon$ and RSM models are shown in Fig. 5 for flow rates of 6 and $8 \mathrm{~m}^{3} / \mathrm{hr}$. Figures 4 and 5 show the distribution of water depth on the spiral trough qualitatively and the quantitative measure (numerical values) is shown in Figure 3. The purpose of Figures 4 and 5 is to show the effect of flow rates on the distribution of water depth. It is clear from Figures 4 and 5 that the depth of water increases with the increase of flow 
rates for all turbulence models. Table 2 shows the maximum values of water depth in the outer region of the trough.

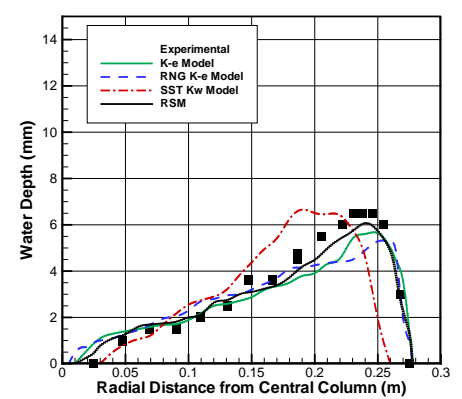

(a) Flow rate $4 \mathrm{~m}^{3} / \mathrm{hr}$.

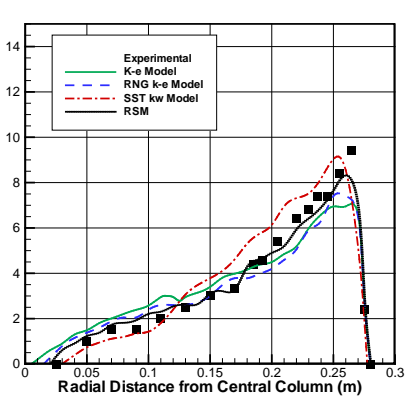

(b) Flow rate $6 \mathrm{~m}^{3} / \mathrm{hr}$.

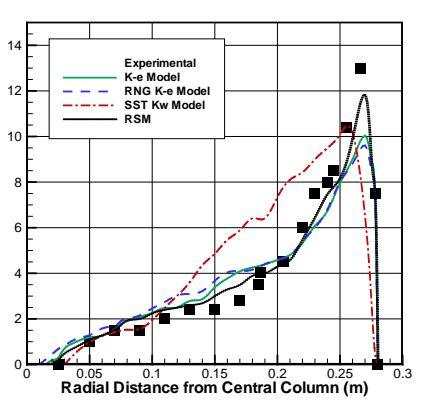

(c) Flow rate $8 \mathrm{~m}^{3} / \mathrm{hr}$.

Fig. 3 Present predictions and experimental results [22,23] for water depth profiles.

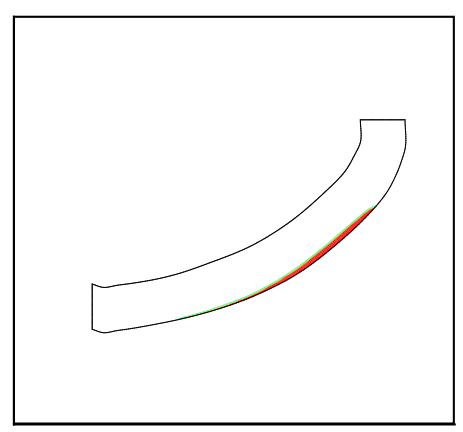

(a) $k-\varepsilon$ Model

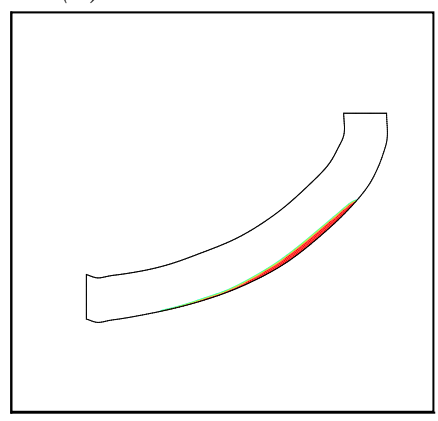

(c) SST k- $\omega$ Model.

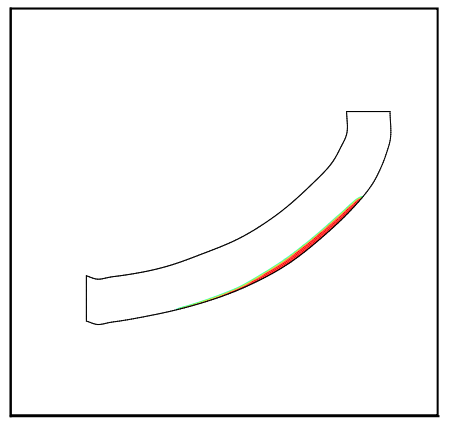

(b) RNG k- $\varepsilon$ Model.

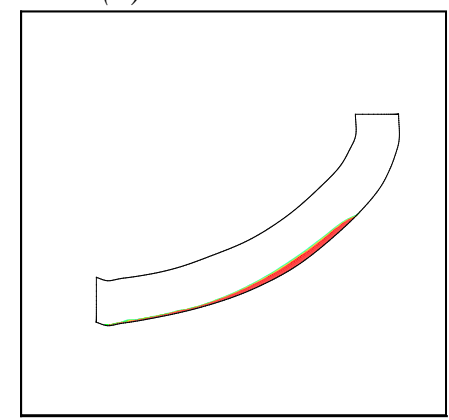

(d) RSM Model.

Fig. 4 Present predictions for water depth profiles, flow rate $4 \mathrm{~m}^{3} / \mathrm{hr}$. 


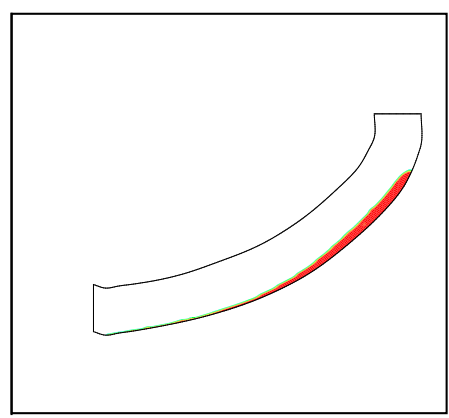

(a)

$R N G k-\varepsilon$ Model, flow rate $6 \mathrm{~m}^{3} / \mathrm{hr}$.

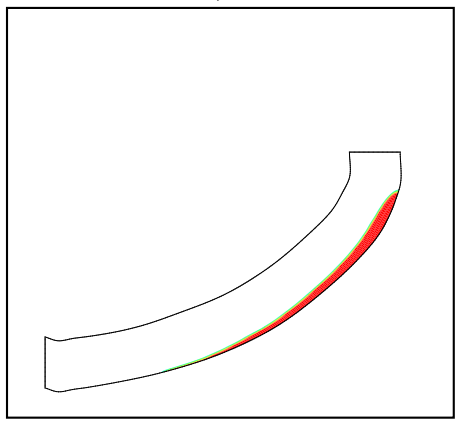

(b) $R N G k-\varepsilon$ Model, flow rate $8 \mathrm{~m}^{3} / \mathrm{hr}$.

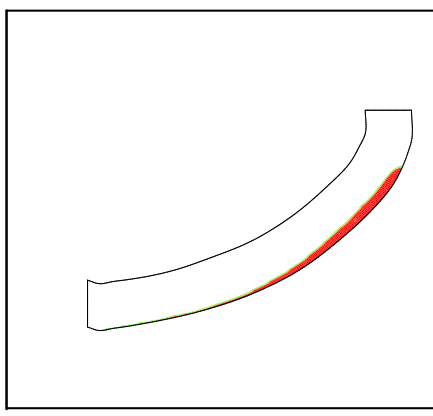

(b) $R S M$ Model, flow rate $6 \mathrm{~m}^{3} / \mathrm{hr}$.

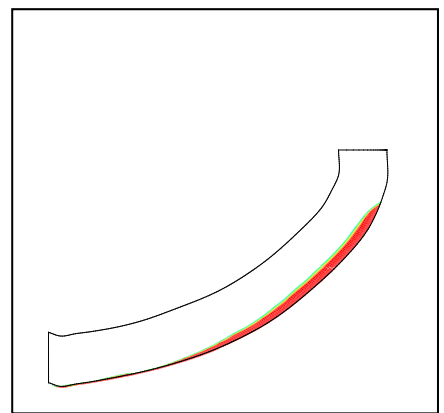

(d) $R S M$ Model, flow rate $8 \mathrm{~m}^{3} / \mathrm{hr}$.

Fig. 5 Present predictions for water depth profiles.

Table (2) Maximum values of water depth in the outer region of the trough.

\begin{tabular}{|l|c|c|c|}
\hline Water flow rate $\left(Q_{\text {water }}\right)\left(\mathrm{m}^{3} / \mathrm{hr}\right)$ & 4 & 6 & 8 \\
\hline Numerical predictions $(\mathrm{mm})$ & 6.08 & 8.32 & 11.8 \\
\hline Experimental results [22,23] $(\mathrm{mm})$ & 6.5 & 9.4 & 13 \\
\hline
\end{tabular}

An error-analysis was carried out using the sum of squares of the difference between predicted and the measured values of water depth. Thus, it was found that the most accurate turbulence model is RSM. Whereas, SST $k-\omega$ model has the lowest accuracy. Details of the error analysis are given in Sec. 4.2.

\subsection{Comparison between Turbulence Models}

To determine the turbulence model that gives best predictions for the investigated problem, a comparison was carried out. The comparison is based on the error between the numerical predictions and the experimental values. The experimental results of Holtham [23] were taken as the reference values. To account for both positive and negative errors, the square of the error is considered. Table 3 shows comparison between different turbulence models. The table covers also the numerical results of others. Each of the values that appear in table 3 represents the summation of the squared-errors at all points of measurements along the radial distance from the central column of the spiral trough. It is noticed that RSM predictions are the closest to the experimental results. Thus, $R S M$ is the best model for computing the flow of spiral separators. It is also obvious that the present predictions of $k-\varepsilon$ and $R N G k-\varepsilon$ are better 
than their corresponding predictions of Mathews et al. [20,21]. Thus, it seems that the present computational scheme gives comparatively good results.

Table (3) Error comparison for different turbulence models.

\begin{tabular}{||c|c|c|c|c|c|c|c||}
\hline \hline No. & Quantity & $\mathbf{k - \varepsilon}$ & $\begin{array}{c}\text { (Mathews et al.) } \\
\mathbf{k - \varepsilon}[\mathbf{2 0 , 2 1}]\end{array}$ & $\begin{array}{c}\text { RNG } \\
\mathbf{k - \varepsilon} \boldsymbol{\varepsilon}\end{array}$ & $\begin{array}{c}\text { (Mathews et al.) } \\
\text { RNG k- } \boldsymbol{\varepsilon}[\mathbf{2 0 , 2 1}]\end{array}$ & $\begin{array}{c}\text { SST } \\
\mathbf{k - \omega}\end{array}$ & $\mathbf{R S M}$ \\
\hline \hline $\mathbf{1}$ & $\begin{array}{c}\text { Water depth } \\
\left(4 \mathrm{~m}^{3} / \mathrm{hr}\right)\end{array}$ & 15.947 & 24.598 & 17.117 & 32.588 & 69.008 & 5.876 \\
\hline $\mathbf{2}$ & $\begin{array}{c}\text { Water depth } \\
\left(6 \mathrm{~m}^{3} / \mathrm{hr}\right)\end{array}$ & 16.518 & 16.773 & 11.323 & 12.670 & 13.988 & 3.588 \\
\hline $\mathbf{3}$ & $\begin{array}{c}\text { Water depth } \\
\left(8 \mathrm{~m}^{3} / \mathrm{hr}\right)\end{array}$ & 21.651 & 22.338 & 26.901 & 43.378 & 18.315 & 9.452 \\
\hline \hline
\end{tabular}

\subsection{Stability Depth}

Stability depth means the water depth at the steady state condition or the final depth on the spiral trough. It is very important to investigate and predict the number of turns that is sufficient (necessary) for the stability of water depth. The number of enough turns is fulfilled when the agreement between predicted water depth and stability depth (final depth) is satisfied. In the present work, the stability depth is taken as the water depth at the end of the sixth turn of the spiral separator. This is because LD9 spiral separator has only six turns.

The stability depth is predicted using $k-\varepsilon$ model at a flow rate of $6 \mathrm{~m}^{3} / \mathrm{hr}$. Case of $k-\varepsilon$ model was chosen to investigate the stability depth because its solution time is the lowest. For the above purpose, five radial locations on the spiral trough were chosen at the outlet of each spiral turn. The radial distances, starting from the central spiral column, of the five radial locations are $5,10,15,20$, and 25 centimeters.

Figure 6 shows that the water depth, after the first spiral turn, is greater than the final depth in the outer region of the spiral trough, whereas, it is smaller in the inner region. It means that the water flow moves toward the outer part of trough at the end of the first turn. After the second spiral turn, the deviation between water depth and final (stability) depth decreases comparing to the first turn. After the third spiral turn, the agreement between water depth and stability depth is about $97 \%$. After the fourth spiral turn, a complete agreement between the water depth and stability depth is achieved. This means that four turns of LD9 spiral separator are enough for the stability of the water flow. This point guides us to examine if this number of turns is enough for the stability of solid particles during future simulation or not. This concept is very important for designers. 

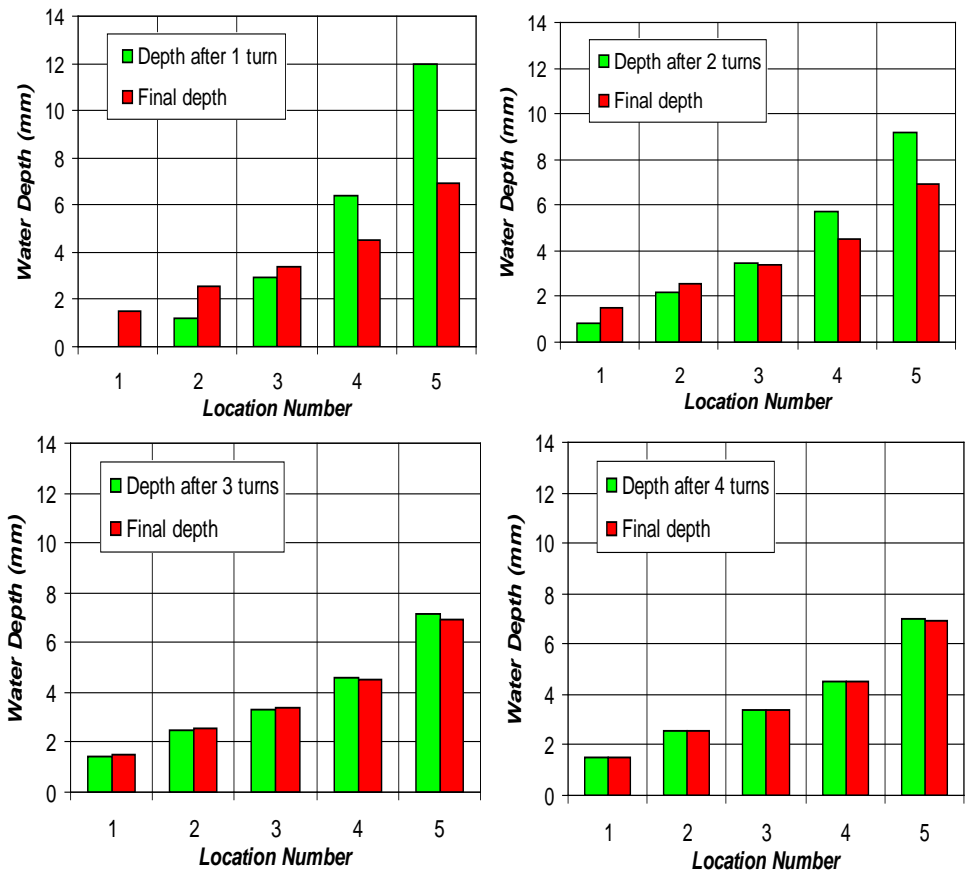

Fig. 6 Change of the water depth with the number of turns at five locations on the spiral trough.

\subsection{Turbulence Intensity}

The turbulence intensity is a scale that characterizes turbulence in percentage. The turbulence intensity (turbulence level) is defined as: ${ }_{T_{i}}=\frac{\sqrt{{u^{\prime 2}}^{2}}}{U}$ Where, $U^{\prime}$ is defined as fluctuations of $u, u=\bar{u}+u^{\prime}$ and $U$ is the mean velocity.

It is clear from Fig. 7 that the values of the turbulence intensity in the outer region of the spiral trough are greater than the corresponding values in the inner region. Maximum turbulence intensity increases with the water flow rate.

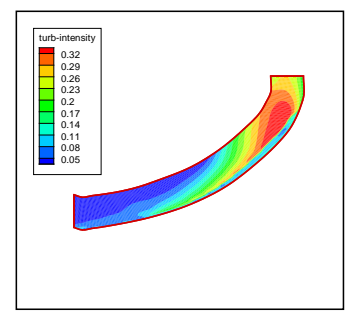

(a) $4 \mathrm{~m}^{3} / \mathrm{hr}$.

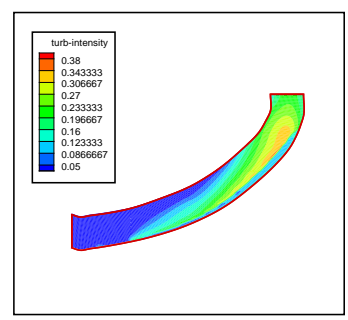

(b) $6 \mathrm{~m}^{3} / \mathrm{hr}$.

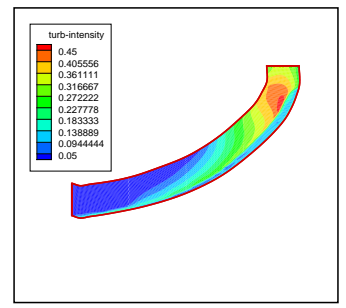

(c) $8 \mathrm{~m}^{3} / \mathrm{hr}$.

Fig. 7 Predictions of turbulence intensity by RSM model for different flow rates.

\subsection{Computational Run-Time}


The computations were carried out using a personal computer $(P C)$ with the following specifications:

1- Processor: Intel Pentium 4 (3.2 GHz, Cache $2 \mathrm{MB})$.

2- Memory : 4 GB Ram.

3- Hard disk: 160 GB.

Table (4) Comparison of the run time for different turbulence models.

\begin{tabular}{|c|c|c|c|}
\hline No. & $\begin{array}{c}\text { Turbulence } \\
\text { model }\end{array}$ & $\begin{array}{c}\substack{\text { Dimensionless } \\
\text { time }} \\
\left(t^{*}=\frac{U_{i n} t_{s}}{L_{c}}\right)\end{array}$ & $\begin{array}{c}\begin{array}{c}\text { Run-time } \\
\text { comparison }\end{array} \\
\left(\frac{t_{\text {Model }}^{*}}{t_{k-\varepsilon \text { Model }}^{*}}\right)\end{array}$ \\
\hline 1 & $k-\varepsilon$ & 11.839 & 1.0 \\
\hline 2 & $R N G k-\varepsilon$ & 12.386 & 1.046 \\
\hline 3 & $S S T k-\omega$ & 12.386 & 1.046 \\
\hline 4 & $R S M$ & 18.943 & 1.600 \\
\hline
\end{tabular}

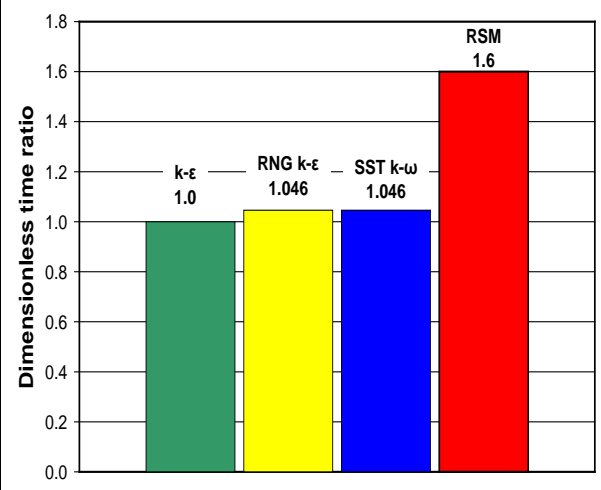

Fig. 8 Dimensionless time ratio for the four turbulence models.

Table 4 and Fig. 8 show a comparison of the run-time for different turbulence models. Where, $U_{\text {in }}$ is the inlet velocity $(\mathrm{m} / \mathrm{s}), t_{\mathrm{s}}$ is the time per a single iteration (Sec.), and $L_{c}$ is a characteristic length $(m)$. Here, it is taken as the stream wise length of one turn of the spiral separator. $t^{*}$ is the non-dimensional time. Table 4 indicates that there is a considerable increase in the run-time when employing the RSM. The increase is $60 \%$ over the run-time of the standard $k-\varepsilon$ model. However, the above discussions showed that the corresponding increase in the accuracy of the computational results is very much noticeable. Thus, it is highly recommended to use RSM in such type of problems. Surely, the rapid development in computer specifications will reduce the run-time of RSM.

\section{CONCLUSIONS}

The suggested numerical scheme has employed four turbulence models, namely: $k-\varepsilon$, $R N G k-\varepsilon$, SST $k-\omega$, and RSM. Two of them (SST $k-\omega$ and RSM models) were not employed before to model the spiral separators. Based on the above discussions, the following conclusions can be stated:

1- Comparisons between the predicted and the measured values indicate that RSM is the most accurate model. This is mainly because RSM contains seven additional transport equations.

2- RSM needs the most computational effort among all turbulence models. It is the most expensive turbulence model compared to the other turbulence models. It requires $60 \%$ more $C P U$ run-time compared to the standard $k-\varepsilon$ model. Moreover, $R S M$ needs more computer memory. 
3- The suggested computational model can be applied to any spiral separator. The geometrical parameters should be modified to the required spiral.

4- The water depth on spiral trough increases with the distance from the central support-column of the spiral. By increasing the flow rate, the water depth increases. The variation of water depth in the outer region is greatly manifested with flow rate. Whereas, small variations are noticed in the inner region as flow rate changes.

\section{REFERENCES}

[1] Burt, R. O., "Gravity Concentration Technology," Elsevier Science Publishers, pp. 261-287, 1984.

[2] Wills, B. A., "Mineral Processing Technology," Fifth edition, Pergamon Press, 1996.

[3] Tuker, P., Lewis, K. A., Hobba, W., and Wells, D., "A Mathematical Model of Spiral Concentration, as Part of a Generalized Gravity-Process Simulation Model, and its Application at Two Cornish Tin Operations," $15^{\text {th }}$ International Mineral Processing Congress, Cannes, France, 3-15,1985.

[4] Tuker, P., "An Approach to Modeling Industrial Unit Process: Application to a Spiral Concentrator for Minerals," J. Appl. Math Modelling, Vol. 9, No.5,pp.375379, 1985.

[5] Kelly, E. G., Gomer J. S., Pillai K. J., Bull, W. R., and Spottiswood, D. J., "The Development and Application of Mathematical Models of Concentrating Spirals," XVI International Mineral Processing Congress, Helsinki, Finland, 1988.

[6] Holland-Batt, A. B., "Spiral Separation: Theory and Simulation," Trans. Inst. Min. Metall. (Sec. C), Vol. 98 (January-April), pp. C46-C59, 1989.

[7] Holland-Batt, A. B., and Holtham, P. N., "Particle and Fluid Motion on Spiral Separators," J. Minerals Engineering, Vol. 4, No. 3-4, pp. 457-482, 1991.

[8] Holland-Batt, A. B., "The Dynamics of Sluice and Spiral Separations," J. Minerals Engineering, Vol. 8, No. 1-2, pp. 3-21, 1995.

[9] Subasinghe, G. K. N. S., and Kelly, E. G., "Predicting the Cut Specific Gravity of a Coal Washing Spiral," J. Minerals Engineering, Vol. 5, No. 2, pp. 193-203, 1992.

[10] King, R. P., Juckes, A. H., and Patricia, A., "A Quantitative Model for the Prediction of Fine Coal Cleaning in a Spiral Concentrator," J. Coal Preparation, Vol. 11, pp. 51-66, 1992.

[11] Loveday, G. K., and Cilliers, J. J., "Fluid Flow Modelling on Spiral Concentrators," J. Mineral Engineering, Vol. 7, No. 2-3, pp. 223-237, 1994.

[12] Atasoy, Y., and Spottiswood, D. J., "A Study of Particle Separation in a Spiral Concentrator," J. Minerals Engineering, Vol. 8, No. 10, pp. 1197-1208, 1995.

[13] Kapur, P. C., and Meloy, T. P., "Spiral Observed," International Journal of Mineral Processing, Vol. 53, pp. 15-28,1998.

[14] Kapur, P. C., and Meloy, T. P., "Industrial Modeling of Spirals for Optimal Configuration and Design: Spiral Geometry, Fluid Flow and Forces on Particles," J. Powder Technology, Vol. 102, pp. 244-252, 1999.

[15] Glass, H. J., Minekus, N. J., and Dalmijn, W. L., "Mechanics of Coal Spirals," J. Minerals Engineering, Vol. 12, No. 3, pp. 271-280, 1999. 
[16] Burch, C. R., "Helicoid Performance and Fine Cassiterite-Contributed Remarks," Trans. Inst. Min. Metall., Vol. 71, pp. 406-415, 1962.

[17] Wang, J. W., and Andrews, J. R. G., "Numerical Simulations of Liquid Flow on Spiral Concentrators," J. Minerals Engineering, Vol. 7, No. 11, pp. 1363-1385, 1994.

[18] Jancar, M. L., Holtham, P. N., Davis, J. J., and Fletcher, C. A. J., "Approaches to the Development of Coal Spiral Models," An International symposium, Soc. Mining, Metal and Exploration, Littliton, USA, pp. 335-345, 1995.

[19] Jancar, T., Fletcher, C. A. J., Holtham, P. N., and Reizes, J. A., "Computational and Experimental Investigation of Spiral Separator Hydrodynamics," Proc. XIX Int. Mineral Processing Congress, San Francisco, USA, 1995.

[20] Matthews, B. W., Fletcher, C. A. J., and Partridge, A. C., "Computational Simulation of Fluid and Dilute Particulate Flows on Spiral Concentrators," Applied Mathematical Modelling, Vol. 22, pp. 965-979, 1998.

[21] Matthews, B. W., Fletcher, C. A. J., Partridge, A. C., and Vasquez, S., "Computations of Curved Free Surface Water Flow on Spiral Concentrators," J. Hydraulic Engineering, Vol. 125, No. 11, pp. 1126-1139, 1999.

[22] Holtham, P. N., "Primary and Secondary Fluid Velocities on Spiral Separators," J. Minerals Engineering, Vol. 5, No.1, pp. 79-91, 1992.

[23] Golab, K. J., and Holtham, P. N.,"Validation of a Computer model of fluid flow on the spiral separator," Innovation in Physical Separation Technologies, Mozely Memorial Symp., Inst. Min. Metall., London,1997.

[24] Davies, P. O. J., Goodman, R. H., and Deschamps, J. A., "Recent Development in Spiral Design, Construction and Application," J. Minerals Engineering, Vol. 4, No. 3-4, pp. 437-456, 1991.

[25] Holland-Batt, A. B., "A Study of the Potential for Improved Separation of Fine Particles by Use of Rotating Spirals," J. Minerals Engineering, Vol. 5, No. 10-12, pp. 1099-1112, 1992.

[26] Matthews, B. W., Fletcher, C. A. J., and Partridge, T. C., "Particle Flow Modeling on Spiral Concentrators: Benefits of Dense Media for Coal Processing?," Second International Conference on CFD in the Minerals and Process Industries, CSIRO, Melbourne, Australia, 6-8 December, 1999.

[27] Hirt, C. W., and Nichols, B. D., "Volume of Fluid (VOF) Method for the Dynamics of Free Boundaries,” J. Computational Physics, Vol. 39, pp. 201-225, 1981.

[28] Harvie, D., and Fletcher, D., "The Stream Volume of Fluid Advection Algorithm," The ANZIAM Journal, Vol. 42 (E), pp. C690-C711, 2000.

[29] Brackbill, J. U., Kothe, D. B., and Zemach, C., "A Continuum Method for Modeling Surface Tension," J. Computational Physics, Vol. 100, pp. 335-354, 1992.

[30] Launder, B. E., and Splading, D. B., "The Numerical Computation of Turbulent Flows," Computer Methods in Applied Mechanics and Engineering, Vol. 3, pp. 269-289, 1974.

[31] Narasimha, M., Sripriya, P. K., and Banerjee, P. K., "CFD Modelling of Hydrocyclone-Prediction of Cut Size," International Journal of Mineral Processing, Vol. 75, pp. 53-68, 2005. 
[32] Yakhot, V., and Orszag, S. A., "Renormalization Group Analysis of Turbulence I. Basic Theory,” Journal of Scientific Computing, Vol. 1, No. 1, pp. 1-51, 1986.

[33] Menter, F. R., "Two-Equation Eddy-Viscosity Turbulence Models for Engineering Applications," AIAA Journal, 32(8), pp. 1598-1605, 1994.

[34] Launder, B. E., Reece, G. J., and. Rodi, W., "Progress in the Development of a Reynolds-Stress Turbulence Closure," J. Fluid Mechanics, 68(3), pp. 537-566, 1975.

[35] Kvicinsky, S., Logatte, F., Kueny, J. L., and Avellan, F., "Free Surface Flows: Experimental Validation of Volume of Fluid (VOF) Method in the Plane Wall Case," Proceedings of the $3^{\text {rd }}$ ASME/JSME Joint Fluids Engineering Conference, San Francisco, California, USA, July 18-23 1999.

[36] Bodnar, T., and Prihoda, J., "Numerical Simulation of Turbulent Free-Surface Flow in Curved Channel," Flow Turbulence Combust, Vol. 76, pp. 429-442, 2006. [37] “Fluent 6.3.26 User’s Guide”, www.fluentusers.com, Fluent Inc., USA, 2006.

\section{التوقع الحسابي لخصائص سريان الماء فى الفاصل الحلزونى الجزء الأول : عمق الماء و شدة الاضطراب}

الفاصل الحلزوني هو أحد أجهزة التركيز بالجاذبية ، ويستخدم على نطاق واسع في معالجة الفحم ، وأيضا يستخدم كوسيلة أولية اقتصادية في معالجة الخامات الفقيرة . الفاصل الحلزوني يتكون من قناة حلزونية مفتوحة ومتماثلة حول محور رأسي .الهدف من هذه الدراسة هو محاكاة سريان الماء في

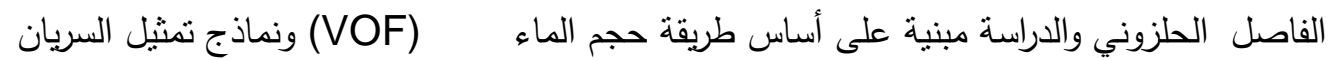
المضطرب • و تركز الدراسة على متغيرات سريان الماء منل عمق الماء وكذلك شدة الاضطراب. وقد أظهرت النتائج أن عمق الماء وشدة الاضطراب على سطح الفاصل الحلزوني تزداد تدريجيا في اتجاه الخارج • تم مقارنة النتائج المحسوبة مع النتائج العملية للحلزون (LD9) المستخدم في معالجة الفحم. وقد أظهرت نتائج المقارنة بين القيم المحسوبة و المقاسة نوافق جيد وان النموذج RSM هو أكثر نماذج تمثيل الاضطراب دقة. 